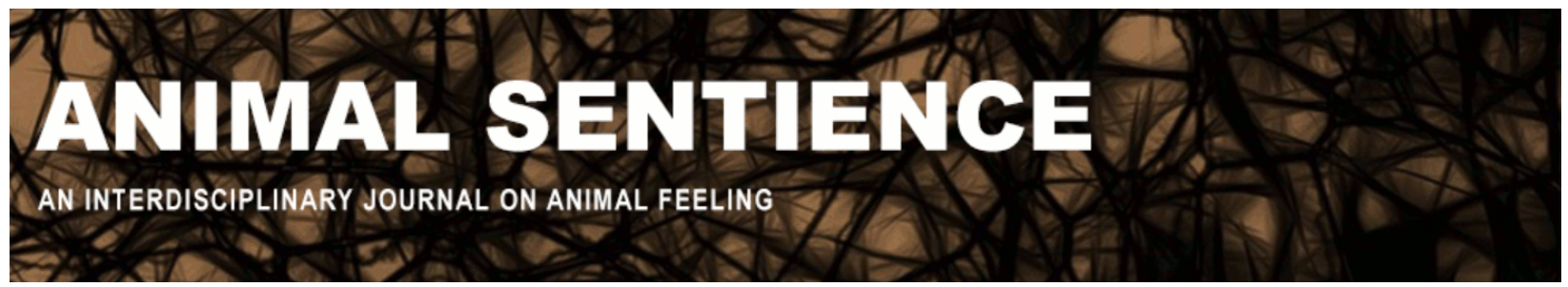

King, James E. (2016) Animal personhood is an evolutionary issue. Animal Sentience 10(12)

DOI: $10.51291 / 2377-7478.1165$

Date of submission: 2016-09-12

Date of acceptance: 2016-09-14 (c) 


\title{
Animal personhood is an evolutionary issue
}

Commentary on Rowlands on Animal Personhood

\author{
James E. King \\ University of Arizona
}

\begin{abstract}
The Rowlands target article makes a case, based on John Locke's metaphysical argument, that personhood can be applied to many species beyond a few nonhuman primates. The problem with this argument is that personhood has an open-ended list of defining attributes and can, at best only be partially applied to nonhuman species. Therefore, a dichotomous distinction cannot be made between qualifying and non-qualifying species. Instead, betweenspecies comparisons must be based on observational and experimental procedures to demonstrate the extent to which human mental attributes are shared with other species. This would allow a more informed view about the appropriateness of personhood in nonhumans.
\end{abstract}

James King is Professor Emeritus of Psychology, University of Arizona. His research has focused on primate behavior including complex learning, infant development, behavioral laterality, and most recently personality and subjective well-being.

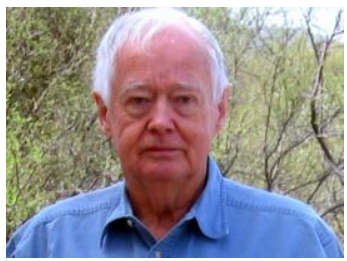
http://bit.ly/JamesKingArizona

Using John Locke's metaphysical approach to defining human personhood, Rowlands (2016) argues for extending personhood to nonhumans. The metaphysical approach to defining personhood is based on defining "what something is," namely, what features it has that confer on it the status of a "person." Since metaphysical concepts cannot be seen directly, this definition comes close to being circular.

Rowlands's specific claim is that a necessary condition for personhood is a capability for pre-reflective awareness, an ability to perceive some event without necessarily having an understanding of the fact that one is aware of that perception. In other words, pre-reflective awareness does not imply the presence of an intentional state. The final conclusion is that there is a "unity" of awareness and mental life that constitutes the basis for personhood.

A fundamental problem with Rowlands's argument is illustrated by his example of a chimpanzee who avoids a desirable food when a more dominant chimpanzee is nearby. Was this a case of higher order intentionality where the submissive chimpanzee knows what the dominant chimpanzee is thinking or is it simply "behavior-reading?" Rowlands suggests that even if it is merely behavior-reading, the chimpanzee meets Locke's test because it passes the test for pre-reflective awareness. In a well-controlled test Hare, Call, \& Tomasello (2001) showed that a submissive chimpanzee's willingness to take food in the presence of a dominant chimpanzee depended upon whether or not the dominant chimpanzee's view of the food was obscured behind a barrier. The submissive chimpanzee's behaviors were consistent with 
reflective awareness and a higher order intentionality and therefore exceeded Locke's criterion for personhood. The low bar of mere pre-reflective awareness would allow attribution of personhood to an absurdly large number of species, primate and non-primate, who would fail Hare's test but still pass a less restrictive test for pre-reflective awareness.

As shown by the target article, a metaphysical approach can be applied to humancentered mental traits. This is possible because terms such as "self," "implicit," reflective," and "nonreflective awareness," "mental life," and "mental unity" have commonly accepted, dictionary-based definitions that can be further refined by metaphysical arguments based on human mentality. However, a critical point is that when mentalistic terms are applied across species, they are only meaningful when based on empirical, data-based evidence. Furthermore, whether these terms, including personhood, are applicable to nonhuman species cannot be answered by a simple yes or no.

"Nature abhors a dichotomy." Evolution in particular abhors a dichotomy for any trait, including species differences in cognitively or mentally related traits. The problem is that descriptions of human traits are open-ended; they are not defined by one specific set of criteria, but by consistency with a list of many criteria that can be augmented at any time and will also vary across species. Attributing the trait of mentality thus becomes a moving target: criteria change often, depending on the viewpoint of the researcher and the context of the data collection. When a mentalistic term is applied to a nonhuman species, some of the human criteria for the term typically generalize to the nonhuman whereas others do not. This is illustrated by examples of three human characteristics that have been partially expressed in great apes: language, morality, and personality. These characteristics do not specifically involve personhood but are relevant to the general argument for animal personhood.

After the first evidence that a chimpanzee could learn to understand and produce sign language (Gardner \& Gardner, 1969) a cascade of criticism emerged (and continues to this day) claiming that the chimpanzee's performance was not related to language but a simpler phenomenon (e.g., Hauser, Chomsky, \& Fitch 2002). A large body of well-controlled research (Gillespie-Lynch, Greenfield, Lynn, \& Savage-Rumbaugh, 2014) nevertheless confirmed that bonobos are capable of mastering many attributes of human language, including generativity or productivity (ability to understand novel sentences). In addition, bonobos are capable of engaging in informal conversations with humans, responding to spoken English with words by means of a hand-held keyboard.

Recent research has demonstrated that chimpanzees have a rudimentary sense of morality in their interactions with conspecifics. Examples include the preference of food-sharing chimpanzees for a token providing food for itself and a conspecific over a token providing food only for itself (Horner, Carter, Suchak, \& de Waal, 2011), as well as more general sharing (Warneka \& Tomasello, 2015) and empathy (de Waal, 2008) among conspecifics.

The third domain showing a continuity between humans and animals is the structure of personality differences. King \& Figueredo (1994) demonstrated a similarity between the human Big Five personality dimensions (Extraversion, Agreeableness, Conscientiousness, Neuroticism, and Openness) and personality dimensions of chimpanzees based on personality-descriptive adjectives. Orangutans (Weiss, King, \& Perkins, 2006) likewise display a personality structure resembling that of humans. The relationship of personality dimensions to rated subjective well- 
being in both species is similar to that in humans. There are clear differences across species, but the overall similarities underlying the cross-species differences are striking.

Alfred Russell Wallace (1910) published a book containing a chapter entitled "Is nature cruel?" His remarkable answer was "No." He justified his answer by claiming that evolutionary forces would have inured animals to suffering because responses to the suffering would have reduced fitness in the uncertain and dangerous natural habitat. An additional claim was that any susceptibility to suffering was directly related to intelligence. Therefore, only humans with their intelligence vastly exceeding that of any animal could be susceptible to agonies and suffering. Unfortunately, Wallace's view is still consistent with the attitudes of many people towards animals. This view of a dichotomy between humans and nonhumans can be countered by showing that animals are sentient, self-aware beings with capacities for suffering, emotions, and empathy not unlike our own. The three examples noted above are consistent with a narrowing of the human-animal distinction and not only refute Wallace's assertion but are also relevant to the issue of personhood beyond the human.

\section{References}

de Waal, F. B. M. (2008). Putting the altruism back into altruism: The evolution of empathy. Annual Review of Psychology, 59, 279-300. doi:10.1146/annurev.psych.59.103006.093625

Gardner, R. A., \& Gardner, B. T. (1969). Teaching sign language to a chimpanzee. Science, 109, 664-672.

Gillespie-Lynch, K., Greenfield, P. M., Lynn, H., \& Savage-Rumbaugh, S. (2014). Gestural and symbolic development among apes and humans: Support for a multimodal theory of language evolution. Frontiers in Psychology, 5, 1-10. doi:10.3389/fpsyg.2014.01228

Hare, B., Call, J., \& Tomesello, M. (2001). Do chimpanzees know what conspecifics know? Animal Behaviour, 61, 139-151. doi:10.1006/anbe.2001.1518

Hauser, M. D., Chomsky, N., \& Fitch, W. T. (2002). The faculty of language: What is it, who has it, and how did it evolve? Science, 298, 1569-1579. doi:10.1126/science.298.5598.1569

King, J. E., \& Figueredo, A. J. (1997). The Five-Factor model plus dominance in chimpanzee personality. Journal of Research in Personality, 31, 257-271. doi:10.1006

Rowlands, M. (2016). Are animals persons? Animal Sentience 2016.101.

Wallace, A. R. (1910). The world of life. London: Chapman and Hall.

Warneken, F., \& Tomasellso, M. (2015). The development and evolutionary origins of human helping and sharing. In D. C. Schroeder \& W. D. Graziano (Eds.), The Oxford handbook of prosocial behavior (pp. 100-113). New York: Oxford University Press.

Weiss, A., King, J. E., \& Perkins, L. (2006). Personality and subjective well-being in orangutans. Journal of Personality and Social Psychology, 90, 501-511. doi:10.1037/0022-3514.90.3.501 